\title{
Declining prevalence of duodenal ulcer at endoscopy in Ile-Ife, Nigeria
}

\author{
${ }^{1}$ Department of Medicine, College of Health Sciences, Obafemi Awolowo University, Ile-Ife, Nigeria \\ ${ }^{2}$ Department of Medicine, Federal Medical Center, Lokoja, Nigeria \\ ${ }^{3}$ Department of Surgery, College of Health Sciences, Obafemi Awolowo University, Ile-Ife, Nigeria
}

O Ijarotimi, ${ }^{1}$ FWACP; D O Soyoye,${ }^{1}$ FMCP; O Adekanle, ${ }^{1}$ FMCP; D A Ndububa, ${ }^{1}$ FWACP; B I Umoru, ${ }^{2}$ FWACP; O I Alatise,${ }^{3}$ FMCS, FWACS

Corresponding author: O Ijarotimi (segjarot@hotmail.com)

Background. Duodenal ulcer is the most common peptic ulcer disease worldwide. In the past, sub-Saharan Africa has been described as an area of mixed prevalence for peptic ulcer disease, but recent reports have disputed this. Changes in the prevalence of duodenal ulcer have been reported, with various reasons given for these.

Objective. To describe the change in endoscopic prevalence of duodenal ulcer at Obafemi Awolowo University Teaching Hospital (OAUTH), Ile-Ife, Nigeria, between January 2000 and December 2010.

Methods. This was a retrospective, descriptive study of patients who underwent upper gastrointestinal endoscopy in the endoscopy unit of OAUTH between January 2000 and December 2010. The data were obtained from the endoscopy register, demographic indices, presenting symptoms and post-endoscopic diagnoses being retrieved for each patient. The study period was divided into the years 2000 - 2004 and 2005 - 2010, the frequencies of duodenal ulcer and other post-endoscopic diagnoses being compared between these two time periods to see whether there were changes.

Results. Over the study period, 292 patients (15.8\%) were diagnosed with duodenal ulcer, second only to 471 patients (26.2\%) with acute gastritis. The prevalence of duodenal ulcer for 2000 - 2004 was $22.9 \%$ ( $n=211$ patients) compared with $9.2 \%$ ( $n=81)$ for $2005-2010$ ( $p<0.001$ ). Conclusion. There was a significant decline in the endoscopic prevalence of duodenal ulcer over the decade.

S Afr Med J 2017; 107(9): 750-753. DOI: 10.7196/SAMJ.2017.v107i9.12342

Duodenal ulcer is the most common peptic ulcer disease worldwide. It is commoner than gastric ulcer. ${ }^{[1]}$ It is not easy to distinguish between the two on the basis of the clinical presentation alone, so patients require upper gastrointestinal endoscopy to visualise and identify each ulcer. A decreasing prevalence of peptic ulcer disease has been observed in North America ${ }^{[2]}$ and the Asia-Pacific region. ${ }^{[3]}$ Several reasons have been suggested for this decline.

The actual prevalence of duodenal ulcer in the general population is difficult to determine, because upper gastrointestinal endoscopy is not routinely done for every patient with dyspepsia. Most patients who do not undergo endoscopy are aged $<45$ years, with previously uninvestigated and uncomplicated dyspepsia. ${ }^{[4]}$ This age cut-off may vary between countries, depending on the prevalence of gastric cancer. Over-prescription and indiscriminate use of drugs such as antibiotics ${ }^{[5]}$ and proton pump inhibitors ${ }^{[6]}$ can also affect the prevalence of duodenal ulcer. Both drugs have activity against Helicobacter pylori, a major risk factor for peptic ulcer disease worldwide. ${ }^{[7]}$ Their effects can be curative when both are used as part of triple or quadruple anti-Helicobacter therapy. However, they can lead to temporary resolution of ulcer symptoms even when they are not correctly used as part of such a regimen. They can also cause temporary suppression of the $H$. pylori activity in such cases.

\section{Objective}

To describe the changing endoscopic prevalence of duodenal ulcer between January 2000 and December 2010 at Obafemi Awolowo University Teaching Hospital (OAUTH), Ile-Ife, Nigeria.

\section{Methods}

This was a retrospective, descriptive study of patients who underwent upper gastrointestinal endoscopy at the endoscopy unit of OAUTH.
The study data were retrieved from the endoscopy register, where the demographic data, indications for the procedure and endoscopic findings are recorded for all patients.

The study participants were all patients who underwent complete upper gastrointestinal endoscopy during the study period January 2000 - December 2010. The data were collected per endoscopy and not per patient, i.e. the information was based on the number of procedures done over this time period and not the number of patients. This allowed for quick and easy data collection. (In the article, however, we refer to patients and give numbers of patients. Although the data were collected based on the number of procedures, so some patients may have had more than one procedure during the study period, we believe that the incomplete procedures and missing diagnoses that were excluded from the study probably negate the effect of data duplication and bring the situation closer to one patient $=$ one procedure. We also believe that the large sample size makes any minimal data duplication insignificant with regard to the main outcome of the study.) All aborted procedures were excluded from the study, as the full extent of the diagnosis might not be known. They were mostly rescheduled for another time. This was helpful in limiting the duplication of data.

Variables analysed were demographic data (age and sex of patients), presenting symptoms (the indications for upper gastrointestinal endoscopy), and post-endoscopic diagnoses (the diagnoses made on the basis of the findings).

\section{Procedure}

All the patients fasted overnight before the procedure. They all consented to the procedure after full information had been provided to them. The procedure was done with the patient conscious and lying in the left lateral position. 
Topical pharyngeal anaesthesia was achieved with $10 \%$ xylocaine spray. This was followed by the intravenous injection of midazolam $2.5 \mathrm{mg}$ or diazepam $5 \mathrm{mg}$, depending on which was available at the time. The exceptions were individuals in whom sedatives/hypnotics were contraindicated. Patients were also given $20 \mathrm{mg}$ hyoscine butylbromide intravenously before the start of the procedure.

\section{Data collection}

The data were collected between the years 2000 and 2010. Demographic data, presenting symptoms and post-endoscopic diagnoses, where available, were retrieved for each patient over this time period. The study period was divided into the years 2000 - 2004 and 2005 - 2010, and the variables were compared between these two periods to see whether there were changes in their frequency of occurrence between the first half of the study period and the latter half.

\section{Statistical analysis}

Data were analysed using the Statistical Package for the Social Sciences (SPSS), version 21.0 (IBM, USA). Medians and ranges were calculated for continuous variables, whereas proportions and frequency tables were used to summarise categorical variables. The Mann-Whitney $U$-test, a non-parametric test, was used to compare the median ages between the two study periods. The $\chi^{2}$ test and logistic regression analysis were used to test for significance of association between the independent (predictor) and dependent (outcome) variables for categorical variables. The level of significance was set at $p<0.05$.

\section{Ethics and approval}

All patients gave written informed consent for the procedure. Ethical clearance was obtained from the OAUTH Ethics and Research Committee (ref. no. IRB/IEC/0004553: NHREC/27/02/2009a).

\section{Results}

\section{Demographic characteristics}

A total of 1937 patients underwent upper gastrointestinal endoscopy during the study period, of whom 138 were excluded owing to missing post-endoscopic diagnoses or incomplete procedures. A total of 1799 patients were therefore included in the study, of whom 986 were males (54.8\%) and 813 females (45.2\%). The ages of the patients ranged from 3 to 100 years (median 45). There was no significant difference in the sex distribution between the years 2000 - 2004 and
2005 - $2010(p=0.169)$ (Table 1). However, there was a significant difference in median ages between the years $2000-2004$ and 2005 $2010(p=0.044)$ (Table 1).

\section{Presenting symptoms}

Dyspepsia was the commonest indication for upper gastrointestinal endoscopy (Table 1). Of the patients, 1335 (74.6\%) presented with dyspepsia and 166 (9.2\%) with upper gastrointestinal bleeding. There was a significant decline in the number of patients who underwent upper gastrointestinal endoscopy for investigation of dyspepsia in 2005 - 2010 compared with 2000 - $2004(p<0.001)$ (Table 1). The number of patients who underwent upper gastrointestinal endoscopy for investigation of upper gastrointestinal bleeding and suspected mitotic lesion increased significantly over the same time periods $(p<0.001)$ (Table 1).

\section{Post-endoscopic diagnoses}

Duodenal ulcers were found in 292 patients (15.8\%); this was second only to acute gastritis $(n=471,26.2 \%)$ (Table 2). Gastric ulcers were found in 237 patients (13.2\%), while gastric erosions were seen in $158(8.8 \%)$.

The frequency of occurrence of duodenal ulcer in $2000-2004$ was $22.9 \%(n=211)$, compared with $9.2 \%(n=81)$ in $2005-2010(p<0.001)$ (odds ratio $0.298,95 \%$ confidence interval 0.222 - 0.400) (Table 3). There was a significant difference in the prevalence of duodenal ulcer between the two time periods, duodenal ulcer being 3.3 times less common in 2005 - 2010 compared with 2000 - 2004.

\section{Discussion}

The overall prevalence of duodenal ulcer in this study was $15.8 \%$ between 2000 and 2010. This is much lower than the $38.7 \%$ reported by Ndububa et al. ${ }^{[8]}$ for the years $1992-1999$. The two studies were done at the same institution but at different times. There was a significant decline in the prevalence of duodenal ulcer, from $22.9 \%$ in $2000-2004$ to $9.2 \%$ in 2005 - 2010. Unexpectedly, the prevalence of gastric ulcer, a peptic ulcer disease like duodenal ulcer, did not fall over the same study periods.

The trend of a decline in duodenal ulcer prevalence has also been reported by other studies in Nigeria, ${ }^{[9]}$ North America ${ }^{[2]}$ and the Asia-Pacific region. ${ }^{[3]}$ It is therefore not unique to our centre. The significant decline in the number of patients who underwent

Table 1. Comparison of age, sex and presenting symptoms of patients undergoing upper gastrointestinal endoscopy between $2000-2004$ and 2005 - 2010

\begin{tabular}{|c|c|c|c|c|}
\hline Variables & $\begin{array}{l}2000-2004 \\
(N=921)\end{array}$ & $\begin{array}{l}2005-2010 \\
(N=878)\end{array}$ & $\begin{array}{l}2000-2010 \\
(N=1799)\end{array}$ & $p$-value \\
\hline Sex, $n(\%)$ & & & & 0.169 \\
\hline Male & $490(53.2)$ & $496(56.5)$ & $986(54.8)$ & \\
\hline Female & $431(46.8)$ & $382(43.5)$ & $813(45.2)$ & \\
\hline Age (yr), median & 45 & 46.5 & 45 & $0.044^{\star}$ \\
\hline \multicolumn{5}{|l|}{ Presenting symptom, $n$ (\%) } \\
\hline Dyspepsia & $733(79.6)$ & $602(68.6)$ & $1335(74.6)$ & $<0.001$ \\
\hline Gastrointestinal bleeding & $58(6.3)$ & $108(12.3)$ & $166(9.2)$ & $<0.001$ \\
\hline Suspected mitotic lesion & $53(5.8)$ & $95(10.8)$ & $148(8.2)$ & $<0.001$ \\
\hline Gastric outlet obstruction & $39(4.2)$ & $36(4.1)$ & $75(4.2)$ & 0.907 \\
\hline Liver cirrhosis & $20(2.2)$ & $9(1.0)$ & $29(1.6)$ & 0.061 \\
\hline Foreign body & $4(0.4)$ & $2(0.2)$ & $6(0.3)$ & 0.688 \\
\hline Other $^{\dagger}$ & $10(1.1)$ & $16(1.8)$ & $26(1.4)$ & 0.236 \\
\hline
\end{tabular}


Table 2. Post-endoscopic diagnoses $(N=1799)$

\begin{tabular}{|c|c|}
\hline Variables & Patients, $n(\%)^{\star}$ \\
\hline Acute gastritis & $471(26.2)$ \\
\hline Duodenal ulcer & $292(15.8)$ \\
\hline Gastric ulcer & $237(13.2)$ \\
\hline Atrophic gastritis & $188(10.5)$ \\
\hline GORD & $176(9.8)$ \\
\hline Gastric erosion & $158(8.8)$ \\
\hline Normal endoscopic finding & $155(8.6)$ \\
\hline Gastric tumour & $100(5.6)$ \\
\hline Oesophageal varices & $79(4.4)$ \\
\hline Gastric polyp & $20(1.1)$ \\
\hline Duodenal polyp & $12(0.7)$ \\
\hline Oesophageal tumour & $13(0.7)$ \\
\hline Early gastric cancer & $26(1.4)$ \\
\hline Other $^{\dagger}$ & $69(3.8)$ \\
\hline \multicolumn{2}{|c|}{$\begin{array}{l}\text { GORD = gastro-oesophageal reflux disease. } \\
\text { *Some patients had multitile pathologies, so the post-endoscopic diagnoses outnumber } \\
\text { the total number of patients and the percentages total more than 100\%. } \\
\text { 'Oesophageal stricturereulcers//erosions, achalasia, foreign-body ingestion, external } \\
\text { compression of the stomach/duodenum. }\end{array}$} \\
\hline
\end{tabular}

upper gastrointestinal endoscopy to investigate dyspepsia over the study period further supports a true decline in the prevalence of duodenal ulcer. Several reasons were given for this decline in North America and the Asia-Pacific region. They were a reduced prevalence of $H$. pylori infection, improved hygiene and improved eradication of $H$. pylori. $^{[2,3]}$ This is not the case in Nigeria, where the incidence of $H$. pylori infection is still very high. ${ }^{[10]}$

Overprescription and widespread use of drugs such as antibiotics ${ }^{[5]}$ and proton pump inhibitors ${ }^{[6]}$ could also be responsible for the decline in duodenal ulcer prevalence. H. pylori is a major risk factor for duodenal ulcer ${ }^{[7]}$ It is responsive to both proton pump inhibitors and antibiotics, either partially or completely. Increased use of proton pump inhibitors and antibiotics, albeit for other reasons, could therefore suppress this organism and encourage temporary healing and resolution of the symptoms of duodenal ulcer. There is widespread indiscriminate use of antibiotics in Nigeria. ${ }^{[5]}$ We did not document the overuse of proton pump inhibitors in our patients, our study being a retrospective one; in fact, there are currently no Nigerian studies documenting this. However, overuse of these drugs, which have anti-H. pylori and mucosal healing properties, has been documented in other parts of the world. ${ }^{[6]}$ The personal experience of the first author (OI) is that proton pump inhibitors are widely used by patients who come to our centre complaining of dyspepsia. Patients are likely to have used both proton pump inhibitors and antibiotics before they undergo upper gastrointestinal endoscopy, which is usually performed because these empirical treatments have failed. However, the above reason does not explain the non-decline of gastric ulcer prevalence in this study. H. pylori is also a causal agent for gastric ulcer. ${ }^{[7]}$ The widespread use of antibiotics and proton pump inhibitors should also affect the prevalence of gastric ulcer and cause a decline like that of duodenal ulcer, but the prevalence of gastric ulcer was steady over the study period. There was even a rise in prevalence compared with the study done by Ndububa $e t$ al. ${ }^{[8]}$ from $4.7 \%$ in $1992-1999^{[8]}$ to $13.2 \%$ for our study period 2000 2010. Even the prevalence of gastric erosions, which should also be affected by the overuse of proton pump inhibitors, increased - from $2.9 \%{ }^{[8]}$ to $8.8 \%$ in our study. The reasons for the above anomaly are not very clear, considering the decline in the prevalence of duodenal ulcer over the same periods. However, it could be due to the increased use of aspirin and non-steroidal anti-inflammatory drugs in Nigeria over the past two decades. ${ }^{[1]}$ These drugs are prominent causes of gastric ulcers and erosions, and can also cause upper gastrointestinal bleeding. The increased incidence of upper gastrointestinal bleeding in our study could also be due to increased use of aspirin and nonsteroidal anti-inflammatory drugs in Nigeria.

Other factors that may be responsible for the decline in the prevalence of duodenal ulcer over the study period should be considered because of the unexpected difference in the changing prevalence patterns of duodenal ulcer and gastric ulcer. One of these is the expertise of the endoscopist - his or her ability to achieve duodenal intubation and to recognise gastrointestinal lesions, including duodenal ulcer. Several endoscopists did the endoscopies in our study, from both the surgical and medical specialties. They had differing levels of competence. Whether this variation in competence is sufficient to affect the apparent prevalence of duodenal ulcer is a question that is difficult to answer. Auditing the upper gastrointestinal endoscopic procedures done by each individual endoscopist would show each one's contribution to the prevalence of duodenal ulcer over the study period. Only then would we know whether levels of competence in fact played a major role.

Table 3. Comparison of prevalences of post-endoscopic diagnoses between 2000 - 2004 and 2005 - 2010

\begin{tabular}{|c|c|c|c|c|c|c|}
\hline Diagnosis & $\begin{array}{l}2000-2004^{*} \\
(N=921) \\
n(\%)^{\dagger}\end{array}$ & $\begin{array}{l}2005-2010 \\
(N=878), \\
n(\%)^{\dagger}\end{array}$ & B & $p$-value & OR & $95 \% \mathrm{CI}$ \\
\hline Duodenal ulcer & $211(22.9)$ & $81(9.2)$ & -1.211 & $<0.001$ & 0.298 & $0.222-0.400$ \\
\hline Gastric ulcer & $117(12.7)$ & $120(13.7)$ & -0.140 & 0.352 & 0.870 & $0.648-1.167$ \\
\hline Acute gastritis & $249(27.0)$ & $222(25.3)$ & -0.304 & 0.010 & 0.738 & $0.586-0.929$ \\
\hline Atrophic gastritis & $93(10.1)$ & $95(10.8)$ & -0.158 & 0.333 & 0.854 & $0.620-1.175$ \\
\hline GORD & $90(9.8)$ & $86(9.8)$ & -0.212 & 0.202 & 0.809 & $0.585-1.120$ \\
\hline Gastric erosion & $79(8.6)$ & $79(9.0)$ & -0.065 & 0.708 & 0.937 & $0.668-1.315$ \\
\hline Oesophageal varices & $29(3.1)$ & $50(5.7)$ & 0.287 & 0.242 & 1.332 & $0.823-2.156$ \\
\hline Gastric tumour & $61(6.6)$ & $39(4.4)$ & -0.683 & 0.002 & 0.505 & $0.330-0.774$ \\
\hline Oesophageal tumour & $10(1.1)$ & $3(0.3)$ & -1.446 & 0.029 & 0.235 & $0.064-0.863$ \\
\hline Gastric polyp & $11(1.2)$ & $9(1)$ & -0.251 & 0.586 & 0.778 & $0.315-1.922$ \\
\hline Duodenal polyp & $3(0.3)$ & $9(1)$ & 0.859 & 0.201 & 2.361 & $0.633-8.807$ \\
\hline
\end{tabular}


Our hospital is a tertiary institution and referral centre, and we probably do not see many uncomplicated cases of peptic ulcer disease. These patients are likely to consult their primary care physicians because of ease of access, and will only be referred if they develop complications. This apparent reduction in the burden of duodenal ulcer could be misinterpreted as a reduction in its prevalence. There was an increase in the number of patients who underwent upper gastrointestinal endoscopy in our study ( $N=1799)$ compared with the study by Ndububa et al. ${ }^{[8]}$ in the same endoscopy unit $(N=834)$. However, this did not translate into an increased prevalence of duodenal ulcer - instead, there was a decrease in prevalence over the two decades. The reduction in duodenal ulcer prevalence was therefore not due to a reduced number of endoscopic referrals, as the reverse is the case. Instead it may be due to the choice of patients being referred, as explained above. However, referral bias may not have as much effect as would be expected, because most endoscopies are done in tertiary institutions like ours. Our results were based mainly on endoscopic diagnoses of duodenal ulcer, and not symptomatic diagnoses. Furthermore, referral bias does not explain why the prevalence of duodenal ulcer decreased, while that of gastric ulcer did not.

Upper gastrointestinal endoscopy is not routinely done for patients with dyspepsia, especially those aged $<45$ years ${ }^{[4]}$ despite dyspepsia being a major symptom of peptic ulcer disease (the exceptions being patients with symptoms or signs that may suggest gastrointestinal bleeding, gastrointestinal malignancy or gastric outlet obstruction). ${ }^{[12]}$ This is because the risk of gastric cancer is low in this age group and most of these patients have negative endoscopic findings. This is intended as a cost-saving measure, and a means of avoiding the possible complications of endoscopy. However, it would prevent the actual prevalence of duodenal ulcer from being known, especially in patients aged $<45$, as it would lead to a falsely reduced endoscopic prevalence of duodenal ulcer. Most patients aged $<45$ are treated empirically or on the basis of non-invasive tests for $H$. pylori such as a urea breath test and a stool antigen test. However, this also does not explain the difference in prevalence between gastric and duodenal ulcer.

\section{Study limitations}

A limitation of the study is that it is retrospective. The information was collected from a joint surgical and medical endoscopy register, and there was no way to obtain more than what was recorded there. Furthermore, there was no way to go back and review the diagnoses, as they were based on a one-time-look procedure by the endoscopist.

Another important limitation of this study is that the patients whose records were analysed may not be representative of the general population, because it was a hospital-based study and not a community-based one.

A further limitation is that the data were collected on a per endoscopy basis and not per patient. This would have led to duplication of some data and could have affected the validity of the results. However, it is difficult to ascertain the magnitude of this effect, and whether it would have led to an increase or a decrease in the endoscopic prevalence of duodenal ulcer.

\section{Conclusion}

This study showed a decline in the endoscopic prevalence of duodenal ulcer over the decade 2000 - 2010 in our institution. The significant reduction in the number of patients who underwent upper gastrointestinal endoscopy to investigate dyspepsia over the study period further supports a true decline in the prevalence of duodenal ulcer. The reasons for this decline are not entirely clear, although several have been considered. These include widespread use of proton pump inhibitors and antibiotics by patients before endoscopy, differing competences of the endoscopists who contributed to the endoscopic data, non-referral of many uncomplicated cases of dyspepsia to our tertiary institution, and the general rule of not routinely doing upper gastrointestinal endoscopy for patients with uncomplicated dyspepsia, especially those aged $<45$ years.

Studies done in North America and the Asia-Pacific region have attributed this decline to increased eradication and a reduced prevalence of $H$. pylori infection. ${ }^{[2,3]}$ Although studies in Nigeria have shown that the prevalence of $H$. pylori is still high, ${ }^{[10]}$ we recommend that future research includes the $H$. pylori status of patients. This will help to ascertain whether a reduction in $H$. pylori prevalence is also responsible for the decline in duodenal ulcer prevalence in our environment.

Acknowledgements. We thank the members of the nursing staff of the endoscopy unit for their help in data retrieval.

Author contributions. OI: Study conception and design, retrieval and collation of data, data analysis and interpretation of data after analysis, writing up the article; DOS: collation of data, data analysis and interpretation of data after analysis, revising the article and approval of the final version; OA: collation of data and interpretation of data after analysis, revising the article and approval of the final version; DAN: study conception, collation of data and interpretation of data after analysis, revising the article and approval of the final version; BIU: collation of data and interpretation of data after analysis, revising the article and approval of the final version; OIA: collation of data and interpretation of data after analysis, revising the article and approval of the final version. All the authors except DOS are endoscopists whose patients were included as part of the data.

Funding. None (the study was self-funded).

Conflicts of interest. None.

Longmore M, Wilkinson I, Baldwin A, Wallin E. Oxford Handbook of Clinical Medicine. Oxford: Oxford University Press, 2014

2. El-Serag H, Sonnenberg A. Opposing time trends of peptic ulcer and reflux disease. Gut 1998;43(3):327-333. https://doi.org/10.1136/gut.43.3.327

3. Wong SN, Sollano JD, Chan MM, et al. Changing trends in peptic ulcer prevalence in a tertiary care setting in the Philippines: A seven-year study. J Gastroenterol Hepatol 2005;20(4):628-632. https://doi. org/10.1111/j.1440-1746.2005.03719.x

4. Malfertheiner P, Megraud F, O'Morain C, et al. Current concepts in the management of Helicobacter pylori infection: The Maastricht III Consensus Report. Gut 2007;56(6):772-781. https://doi.

5. Olayemi O, Olayinka B, Musa A. Evaluation of antibiotic self-medication pattern amongst undergraduate students of Ahmadu Bello University (Main Campus), Zaria. Res J Appl Sci Eng
ung a 6. (1):35-38.

6. Naunton M, Peterson G, Bleasel M. Overuse of proton pump inhibitors. J Clin Pharm Ther 2000;25(5):333-340. https://doi.org/10.1111/j.1365-2710.2000.00312.x

7. Sugano K, Tack J, Kuipers EJ, et al. Kyoto global consensus report on Helicobacter pylori gastritis. Gut 2015;64(9):1353-1367. https://doi.org/10.1136/gutjnl-2015-309252

8. Ndububa D, Agbakwuru A, Adebayo R, et al. Upper gastrointestinal findings and incidence of Helicobacter pylori infection among Nigerian patients with dyspepsia. West Afr J Med 2000;20(2):140-145.

9. Nwokediuko SC, Ijoma U, Obienu O, Picardo N. Time trends of upper gastrointestinal diseases in Nigeria. Ann Gastroenterol 2012;25(1):52-56.

10. Olokoba A, Gashau W, Bwala S, Adamu A, Salawu F. Helicobacter pylori infection in Nigerians with dyspepsia. Ghana Med J 2013;47(2):79-81.

11. Awofisayo $\mathrm{O}$, Awofisayo $\mathrm{O}$, Iferi I, Akpan O. The pattern of sale and use of non-steroidal antiinflammatory drugs in rural and urban centres in Nigeria. Trop J Pharm Res 2008;7(3):1013-1018. hftamms://doiorg drugs in rural and urb

12. Barkun $A$, Leontiadis $G$. Systematic review of the symptom burden, quality of life impairment and costs associated with peptic ulcer disease. Am J Med 2010;123(4):358-366.e2. https://doi.org/10.1016/j. amjmed.2009.09.031

Accepted 22 March 2017 